\title{
Management, Governance and Value Creation in a Blockchain Consortium
}

Zavolokina, Liudmila ; Ziolkowski, Rafael ; Bauer, Ingrid ; Schwabe, Gerhard

\begin{abstract}
In recent years, an increasing number of blockchain consortia have emerged. However, little is known about how these consortia are developed and what tensions emerge in such collaborations. We describe the evolution of the cardossier blockchain consortium in Switzerland, which is building a system for managing car data and seeking to improve collaboration between players in the car-related ecosystem. From our involvement with the cardossier project, we have gained insights that will be valuable for enterprises considering whether to join a blockchain consortium.
\end{abstract}

DOI: https://doi.org/10.17705/2msqe.00022

Posted at the Zurich Open Repository and Archive, University of Zurich

ZORA URL: https://doi.org/10.5167/uzh-178630

Journal Article

Accepted Version

Originally published at:

Zavolokina, Liudmila; Ziolkowski, Rafael; Bauer, Ingrid; Schwabe, Gerhard (2020). Management, Governance and Value Creation in a Blockchain Consortium. MIS Quarterly Executive, 19(1):1-17.

DOI: https://doi.org/10.17705/2msqe.00022 


\title{
Management, Governance and Value Creation in a Blockchain Consortium
}

In recent years, an increasing number of blockchain consortia have emerged.

However, little is known about how these consortia are developed and what tensions

emerge in such collaborations. We describe the evolution of the cardossier blockchain

consortium in Switzerland, which is building a system for managing car data and

seeking to improve collaboration between players in the car-related ecosystem. From

our involvement with the cardossier project, we have gained insights that will be

valuable for enterprises considering whether to join a blockchain consortium. ${ }^{1,2}$

\section{Liudmila Zavolokina}

University of Zurich (Switzerland)

\author{
Rafael Ziolkowski
}

University of Zurich (Switzerland)

Ingrid Bauer

University of Zurich (Switzerland)

\footnotetext{
${ }^{1}$ Carsten Sørensen is the accepting senior editor for this article.

2 This research has been funded by Innosuisse (a Swiss government agency) as part of the "Blockchain Car Dossier" project. This project is a collaborative effort, and many of the ideas presented in this article result from many hours of discussion and endeavor involving the whole project team. We thank all project members for their feedback and involvement, especially Matthias Loepfe from AdNovum, co-initiator and the project manager of the cardossier project, and Gianluca Miscione for his invaluable thoughts and ideas on governance. We also thank the editorial team of this special issue of MIS Quarterly Executive: Mary Lacity, Carsten Sørensen and Rajiv Sabherwal, and the anonymous reviewers for their extensive and very helpful feedback that helped us significantly during the preparation of this article.
} 


\section{Gerhard Schwabe}

University of Zurich (Switzerland) 


\section{Blockchain Consortia are a New Type of Inter- organizational Collaboration}

In recent years, an increasing number of blockchain consortia have emerged. They have become popular with enterprises that want to leverage the potential of blockchain technology and extract real business value from it. Among executives who are aware of the capabilities blockchain technology offers, "18 percent already participate in a consortium, 45 percent are likely to join one, and 14 percent are considering forming one. "3 Although there are different organizational forms in which businesses explore the potential offered by blockchain technology (e.g., a startup, a traditional enterprise, a consortium $^{4}$ ), blockchain consortia represent a new type of inter-organizational collaboration for exploring the technology, assessing its capabilities and developing digital ecosystems and platforms to solve shared business problems.

The media frequently reports on new inter-organizational collaborations that use the capabilities of blockchain technology and reinvent industries. However, many aspects of these collaborations remain out of sight. Little is known about how blockchain consortia are formed, what role each consortium member plays, what challenges members face in collaborating and what aspects a digital transformation leader should consider when deciding whether to join a blockchain consortium.

\footnotetext{
${ }^{3}$ Gratzke, P., Schatsky, D. and Piscini, E. Banding together for blockchain: Does it make sense for your company to join a consortium? Deloitte Insights, August 16, 2017, available at https:/www2.deloitte.com/insights/us/en/focus/signals-for-strategists/emergence-of-blockchainconsortia.html.

${ }^{4}$ Lacity, M. C. "Addressing Key Challenges to Making Enterprise Blockchain Applications a Reality," MIS Quarterly Executive (17:3), September 2018, pp. 201-222.
} 
In this article, we provide insights gained from our participation in the cardossier ${ }^{5}$ project, which is developing a blockchain solution and consortium for sharing data relating to cars. The aim of cardossier is to manage the lifecycle of a car and thus improve collaboration between garages, insurers, state agencies and other players in the used-car market. Based on our active involvement with the cardossier project over a three-year period, we provide a rich description of the consortium. We identify six tensions the consortium faced within three major areas (consortium management, business value and governance) and describe the way these tensions were resolved. The insights we gained will help organizations to benefit from collaborating in a blockchain consortium.

\section{The Growth and Diversity of Blockchain Consortia}

According to Wikipedia, a consortium is "an association of two or more individuals, businesses, organizations or governments (or any combination of these entities) with the objective of participating in a common activity or pooling their resources for achieving a common goal." A consortium is a traditional form of cooperation between institutions that see value in sharing resources and know-how, and thus save costs. Such cooperation often emerges in research and development projects, which are characterized by higher risks and costs. ${ }^{6}$ In recent years, the number of blockchain consortia has been steadily growing (from 25 in $2016^{7}$ to 108 in $2019^{8}$ ).

\footnotetext{
${ }^{5}$ The word "cardossier" is derived from "digital car data." For information about the cardossier project, see www.cardossier.ch.

${ }^{6}$ Ring, P. S., Doz, Y. L. and Olk, P. M. "Managing Formation Processes in R\&D Consortia," California Management Review (47:4), July 2005, pp. 137-156.

${ }^{7}$ Mougayar, W. The State of Global Blockchain Consortia, CoinDesk, December 11, 2016, available at https://www.coindesk.com/state-global-blockchain-consortia.
} 
Blockchain consortia can be divided into two types. The first is business-oriented, with consortium members aiming to solve one or more business problems (an example is the $\mathrm{B} 3 \mathrm{i}$ consortium in the insurance industry ${ }^{9}$ ). The second is technology-oriented, where consortium members aim to develop platforms that serve as a universal infrastructure that can be used by different types of businesses (an example is Hyperledger $\left.{ }^{10}\right)$. There are examples of business-oriented consortia becoming technology-oriented (e.g., the R3 consortium, whose members are primarily banks and financial institutions developing a platform, Corda, suitable for transactions of any kind $\left.^{11}\right)$.

Some blockchain consortia are international, while others focus exclusively on local markets. Consortia vary in size, from very small with only two or three members, to large with hundreds of members. Moreover, blockchain consortia may differ in their governance models and business goals. The variety, complexity and nature of this new type of inter-organizational collaboration, combined with growing levels of interest from managers and executives in the use of blockchain technology in enterprises, ${ }^{12}$ calls for deeper understanding of the important factors to consider when deciding whether to join a blockchain consortium. Businesses intending to explore the potential offered by blockchain technology rely critically on the deliberate formation of consortia. However, the formation of blockchain consortia and their success criteria have received little attention in the literature.

\footnotetext{
${ }^{8}$ Top Four Enterprise Blockchain Consortia Trends, ESG Intelligence, June 19, 2019, available https:/esg-intelligence.com/blockchain-articles/2019/06/19/top-four-enterprise-blockchain-consortiatrends-2019/.

${ }^{9}$ For information about B3i, see https://b3i.tech.

${ }^{10}$ For information about Hyperledger, see https://www.hyperledger.org.

${ }^{11}$ For information about R3 and Corda, see https://www.r3.com.

${ }^{12}$ Lacity, M. C., op. cit., September 2018.
} 
This cardossier case study explicitly focuses on the core tensions involved in establishing a viable blockchain consortium. First, we identify the challenges associated with forming a "vertical" consortium that includes non-competing players from the carrelated ecosystem, and we then discuss expansion of the consortium to include competing firms.

\section{Three Phases of the cardossier Consortium's Evolution}

The initial members of the cardossier consortium included multiple stakeholders from the private sector (an insurance company, an importer, an official car dealer, a carsharing company and a software development partner), the public sector (a Swiss Road Traffic Agency) and two research institutions. The consortium was formed to address three specific problems:

- Inconsistent and unreliable data stored by different organizations in local databases

- Costly and cumbersome business processes for businesses and state organizations

- The lack of transparency and trust between individuals and organizations.

The consortium's goal is to build a reliable and secure "single source of truth" that removes the need to rely on a third party for data exchange and audit, and that involves various organizations from the car-related ecosystem with different interests and incentives.

The cardossier consortium has evolved through three main phases - Consortium Formation, Development of the Minimum Viable Product (MVP) and Preparation for Market Entry. Figure 1 shows the timeline of these three phases. The next stage, planned for 2020, is to enter the market. 
Figure 1: Timeline of the cardossier Consortium

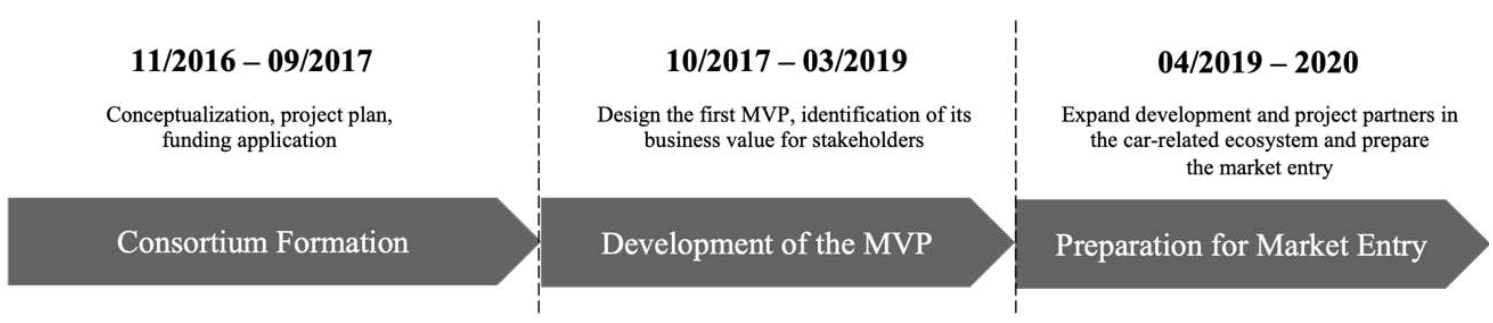

During this three-phase evolution, the consortium faced several paradoxical tensions in three major areas: consortium management, business value and governance. Note, though, that there is overlap between these three areas. For example, governance is closely connected with business value and consortium management. Furthermore, the relative important of the areas varies over time. For example, in Phase 1 consortium management was very important for creating a stable collaboration; governance and business value challenges became more important as the project gets closer to market entry.

\section{Phase 1: Consortium Formation}

The first phase of the cardossier project included activities concerned with conceptualizing the idea, preparing the project and financial plans, and setting up the project. The project started in November 2016 as a research/innovation initiative by AdNovum, ${ }^{13}$ a Swiss software company, and the University of Zurich, ${ }^{14}$ with the initial goal of experimenting with blockchain, then a new technology. Inspired by the promised benefits of blockchain technology (i.e., trust and transparency between transacting parties), the collaboration started informally with idea-generation and conceptualization of the project.

${ }^{13}$ AdNovum (https://www.adnovum.ch/) is a leading security and identity management software provider in Switzerland, covering numerous business domains. 
AdNovum and the researchers set about identifying specific use-cases that could considerably benefit from trust enhancement. After considering several alternatives, the researchers identified the used-car market as a potentially relevant use-case for blockchain technology. This market was chosen because it suffers from a lack of trust and transparency, and there are information asymmetries between used car sellers and buyers. These problems in the used-car market were described in 1970 by Akerlof when he labeled bad secondhand cars as "lemons." 15 Akerlof's analysis is still relevant today, even in countries like Switzerland where levels of trust are relatively high. ${ }^{16}$

Because of these characteristics of the used-car market, the researchers defined trust and transparency as the targeted value proposition for the cardossier project. A blockchain provides data immutability, transaction transparency and network reliability, and promises a trust-free environment and authentication. With blockchain technology, rights and ownership can be transferred and verified, and therefore the technology enables "digital scarcity." 17

The initial idea for the cardossier project was to document the history of a car and related transactions, and for this documentation to serve as proof of authenticity but not necessarily of transfer of rights. The cardossier business model was conceptualized as a data market that would financially incentivize data exchange: "Data consumers will pay for access to the data, whereas data suppliers, data owners and, to a smaller extent, the

\footnotetext{
${ }^{14}$ Five information systems researchers from the University of Zurich are involved in the design and evaluation of the cardossier blockchain platform. Four of them are the authors of this article.

${ }^{15}$ Akerlof, G. A. "The Market for 'Lemons': Quality Uncertainty and the Market Mechanism," The Quarterly Journal of Economics (84:3), August 1970, pp. 488-500.

${ }^{16}$ For statistics about trust across countries, see Ortiz-Ospina, E. and Roser, M. Trust, Our World in Data, available at https://ourworldindata.org/trust.

17 The best-known example of creating digital scarcity to enhance value is Bitcoin; only 21 million Bitcoins will ever be mined.
} 
operators of the blockchain will be rewarded." 18 The intention was to create a simple app for private users of cardossier that would provide an overview of a car's history. Moreover, private users would be able to monetize data about their cars by providing access to interested parties.

Creating such a system without some form of collaboration would be almost impossible; participation by every type of player in the car-related ecosystem would be needed to collect a vehicle's data. On the one hand, the innovative nature of the project and the desire to quickly develop the technology solution meant that the consortium could not be too large. A smaller number of participants would ensure maneuverability and keep complexity manageable. A smaller consortium would also make it possible to determine early on whether the project would fail or succeed. Early indications of success would enable the consortium to gain a competitive advantage in the fast-growing blockchain application landscape.

On the other hand, the consortium needed a wide range of participants to ensure that comprehensive data covering the full lifecycle of a car could be collected. Thus, several businesses from the car-related ecosystem were invited to participate in the project. They were curious about the consortium because they were aware of the problems and market inefficiencies in the automotive sector, and of the fast-growing fascination about the use of technology. They also feared missing out on important developments in their industry. Some, however, were hesitant about joining the consortium. There were several reasons for their hesitation, which varied from partner to partner, and needed to be overcome. In summary, the main reasons were: (1) dependency on other participating

\footnotetext{
${ }^{18}$ Included in the funding application for the cardossier project.
} 
partners (e.g., for some potential members, a governmental agency being on board was crucial); (2) no clear understanding of benefits the collaboration could offer their businesses; (3) negative reputation of blockchain technology, which might negatively impact their brand image; (4) regulatory constraints; and (5) insufficient resources.

In addition to AdNovum, the University of Zurich and Lucerne University of Applied Sciences and Arts, the following organizations became founder members of the consortium:

- $\mathrm{AMAG},{ }^{19}$ the largest car importer and dealer in Switzerland, which would provide data about car production and import

- A Swiss canton Road Traffic Authority, ${ }^{20}$ which would provide data about registration and regular mandatory checkups

- AXA Winterthur, ${ }^{21}$ an insurance company, which would provide data about insurance policies and accident claims

- Mobility, ${ }^{22}$ a car sharing company, which would provide car usage data (e.g., mileage, services and repairs).

Thus, several businesses from different parts of the car-related ecosystem were invited to participate in the project. However, possible competitors were initially

\footnotetext{
${ }^{19}$ AMAG has extensive knowledge on multiple phases of a car's lifecycle (e.g., its purchase, reselling, maintenance and regulatory aspects).

${ }^{20}$ The Road Traffic Agency has data on many essential aspects of a car's lifecycle and can provide players in the car-related ecosystem with access to crucial data.

${ }^{21}$ AXA Winterthur has data relating to all of the processes in a car's lifecycle associated with car insurance and gains significant benefits from an authenticated car history.

${ }^{22}$ Mobility has extensive knowledge of the car-related ecosystem, and provides the project with insights on a car's lifecycle (e.g., maintenance, insurance claims, car-related data warehousing).
} 
excluded to avoid any conflict between them at the very beginning that might have endangered the project's success.

The cardossier was project seen as a high-risk innovation, which, if successful, would bring value to car-related businesses in Switzerland. However, although the initial project partners acknowledged the need for a solution in the car-related ecosystemspecifically in the used-car market - they were not willing to commit more resources or engage further at this stage. Thus to get the project off the ground, an application for research funding was prepared between October 2016 and May 2017, and submitted to Innosuisse ${ }^{23}$ the government agency that fosters innovation projects with clear business value for the Swiss market. The application was successful and the funding helped to reduce the barriers to participation, encouraged the involvement of other organizations and demonstrated support from the government. These factors, together with the innovative nature of the project and awareness of the problems to be addressed by the project, fostered the successful formation of the consortium.

\section{Phase 2: Development of the Minimal Viable Product}

Phase 2 of the cardossier project included activities concerned with designing the system itself and identifying its business value for consortium members. When this phase started in October 2017, there was no specific structure for communication between participants. In total, around 20 participants were involved in the project, including members of the steering committee, the development and research teams, and industry partners. Participants were geographically distributed and did not have any experience of working together, and the project was innovative in terms of technology

\footnotetext{
${ }^{23}$ For information about Innosuisse, see https:/www.innosuisse.ch/inno/en/home.html.
} 
used and skills needed. The leaders of the project needed to work out how to establish communication between participants and create a common vision for the project. To ensure that all project members were not only up to date but also able to contribute to the project, an early decision was to set up regular meetings and calls. Given that innovation projects in general involve high levels of uncertainty and are experimental, the cardossier project had to be able to react to high levels of volatility in the requirements, Because of this, the project decided to use the Scrum software development methodology $\mathrm{y}^{24}$ to implement a permissioned blockchain for the minimal viable product (MVP). The main factors for choosing a permissioned blockchain were:

- The need for a shared common database for car-related data

- The involvement of multiple parties from the car-related ecosystem

- Conflicting interests of different players in the ecosystem

- Lack of willingness to trust a third-party provider

- The need for consensus between involved organizations

- The latest data protection regulations

- The trade-offs with respect to performance of transaction processing. ${ }^{25}$

In theory, a centralized database could have aggregated data events from multiple parties, but the involved businesses realized that this could result in the emergence of a

\footnotetext{
${ }^{24}$ For a brief description of Scrum, see Scrum (software development), available at https://en.wikipedia.org/wiki/Scrum_(software_development).
} 
dominant player in the car-related ecosystem (akin to Google, Apple or Amazon).

Having a single organization collecting and processing all car-related data would create a centralized power that would be a significant threat to, rather than a potential benefit for, individual industry segments and businesses. Thus, it became clear to the consortium that, in addition to the initial experimentation motivation that drove the choice of blockchain technology, economic considerations required a blockchain ledger. As an AdNovum project manager put it: "Of course, we could have solved the collaboration challenges we had without joining a blockchain consortium, but we would still have come up with a blockchain solution."

Another factor ruled out a centralized solution for the cardossier system. Although there was minimal competition among the initial participants (because each industry sector was represented by one business), the goal was to design a system that would be used by competing businesses. The vision is that multiple (ideally all) firms from all carrelated industries should join the consortium in the future and add their data so that the system can be opened up to private users and therefore cover the entire used-car market. With that vision in mind, a centralized solution was not an option.

During the formation phase, the cardossier project had identified that the aim of the consortium was to resolve trust and transparency issues in the used-car market. However, the implementation of the MVP forced the consortium to narrow the scope even further. By analyzing the pain points along the lifecycle of a car, the consortium identified multiple opportunities for generating business value. The problems in the

\footnotetext{
${ }^{25}$ For more on the factors to consider when choosing a blockchain type, see Pedersen, A. B., Risius, M. and Beck, R. "A Ten-Step Decision Path to Determine When to Use Blockchain Technologies," MIS Quarterly Executive (18:2), June 2019, pp. 99-115.
} 
existing car-related ecosystem include inefficiencies in document management during the process of importing a car, inefficient and largely bespoke processes during repair and service of a car, and information asymmetries between car buyers and sellers. To decide which of these problem areas to focus on, the consortium evaluated the business value for each stakeholder involved in each problem area.

If the consortium were to focus on addressing the inefficiencies during the import process, the importer and the road traffic authorities would be the main beneficiaries. If it were to focus on addressing the largely bespoke car repair and service processes, insurance companies and garage services would benefit most, but this approach would not provide sufficient business value for other involved stakeholders. However, addressing the sale of used cars seemed to offer the same level of benefits to each stakeholder. Thus, the cardossier project decided to implement the MVP to support the sale of used cars because this focus would incentivize each stakeholder to provide data for the whole lifecycle of a car, and the stakeholders would later receive returns from the jointly created data market.

Figure 2 shows the prototype cardossier frontend (i.e., the user-facing cardossier app) developed as part of the MVP. This app was developed to be used by buyers and sellers of used cars, and provides basic data on a car to be sold, its history and assessment, and other information collected from data providers in the cardossier consortium. The technical implementation of the MVP backend was based on Corda distributed blockchain ledger technology. 
Figure 2: cardossier Frontend Prototype
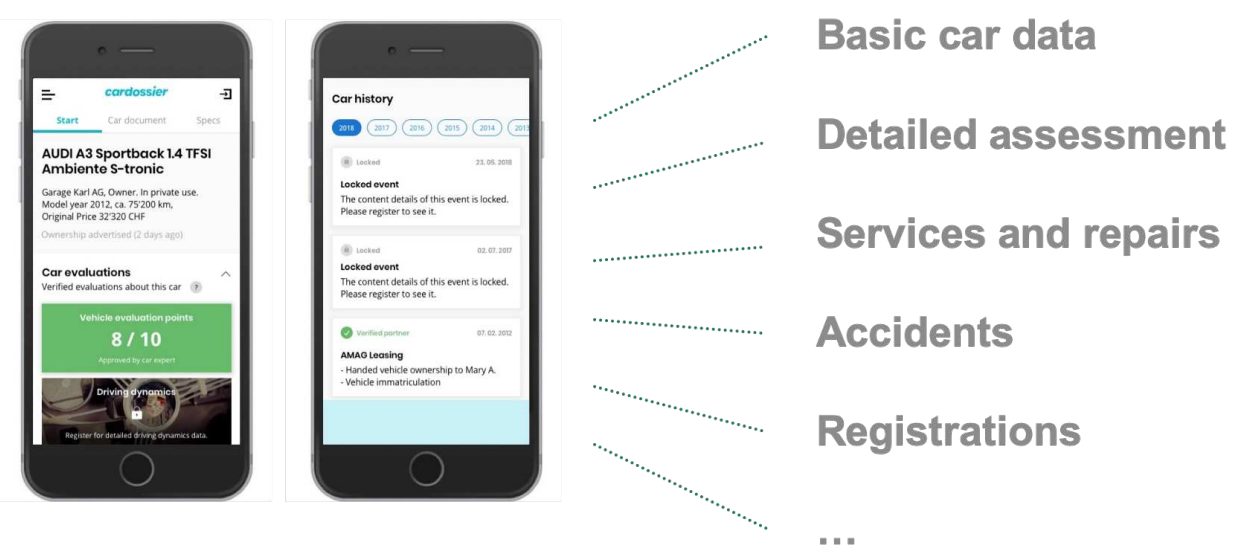

Using blockchain technology for the backend enables the cardossier consortium to establish and store rights over data, which is both an economic and a technical necessity for the consortium. Blockchain technology can manage ownership rights (who owns the data), access rights (who can access the data), exploitation rights (who can use the data), sales rights (who can sell the data) and control rights (who can verify/control the data). Given that multiple parties would be involved in rights management, the consortium chose to implement a distributed ledger. The complex rights management requirements could be met because the stored data was unique and authenticated.

Technically, the consortium created a generic event-based data model and a role model. Certain car-related events, like registration or issuing an insurance policy, as well as the roles of those recording the events, were predefined. For example, insurance policies can only be created by insurance companies, and registration of a car can only be recorded by a registration authority. Recorded events were appended to cars, identified by their vehicle identification numbers. Attributes of the generic event included event ID, event type, event issuer, event owner, business date and a link to the actual content of the event, while the role model provided a mechanism for access control. Data privacy regulations and the design of rights management meant that only 
basic car data was replicated on each blockchain node and thus available to any

consortium member. Detailed event data was replicated only on nodes that had the necessary rights (e.g., ownership or access rights).

\section{Phase 3: Preparation for Market Entry}

The third phase of the evolution (which is ongoing as of mid-2019) includes activities for preparing for market entry and expanding the consortium. During Phase 2, it became apparent that the consortium needed to become a legal entity for four key reasons:

1. To obtain a critical mass of business users, and thus to create the network effects necessary for a successful data market, interested parties needed to sign up to a legal entity

2. To prototype "real" processes, the consortium needed to be a "real" organization

3. As a legal entity, the consortium would be able to sign-up more businesses, and thus, cover more participants from the car-related ecosystem

4. As a legal entity, the consortium would have to adhere to a specific legal framework and comply with the relevant laws, which would help it in its aim of becoming a standard infrastructure for car-related data, and enable it to point to regulatory compliance as a measure of data quality. ${ }^{26}$

\footnotetext{
${ }^{26}$ Government authorities may create incentives for data quality (e.g., by applying sanctions for misusing data records or participants violating the system's rules). Such incentives would address-if not completely resolve - the conflict of interests between different types of users of the cardossier system, such as those providing high-quality data (e.g., owners of good cars, so-called "peaches") and those providing low-quality data or omitting data (e.g., owners of bad cars, so-called "lemons"). For more on data quality, see Zavolokina L., Spychiger, F., Tessone, C. J. and Schwabe, G. "Incentivizing Data Quality in Blockchains for Inter-Organizational Networks - Learning from the Digital Car Dossier," In Proceedings of the 39th International Conference on Information Systems (ICIS 2018), 2018.
} 
On becoming a legal entity, a legally constituted board was created with responsibilities for investing in data protection measures, complying with the legal framework and creating legal guidelines for the consortium and its individual members. The board had authority over the CEO and his office, with the CEO acting with a degree of autonomy on behalf of the consortium's members. This hierarchical structure created a tension that we discuss later in this article.

As mentioned earlier, the cardossier consortium was initially restricted to noncompeting businesses from different parts of the car-related ecosystem. This was done to reduce the complexity of project management, while also obtaining data relating to most of a car's lifecycle (production and import, insurance, registration, usage data, etc.). However, the overall goal is to encompass the entire car-related ecosystem. To achieve this goal and ensure the project's success, it would be necessary to sign up other businesses because:

1. The system critically depends on the availability of car-related data; active data providers and consumers are crucial for the success of cardossier.

2. Creation of a gap-free vehicle history is possible only if all market participants provide data about events throughout a car's lifecycle and make this data available for further use. For example, a single insurance company cannot provide data about insurance policies for all cars in the country; the participation of other insurance companies is needed to cover the whole market.

3. Developing a commercial system, and other activities, such as project management, legal support, marketing and infrastructure, needs additional finance, and the consortium needs to recruit additional members to provide this finance. Although 
the founding members of the consortium agreed there was a need to expand to the broader market, funding this expansion remains one of the biggest challenges and risks for the consortium.

In general, as development of the cardossier system progressed, the value perspective shifted. Starting with the vision of providing an innovative product to meet the needs of an underserved market, the consortium members jointly created a distributed blockchainbased application. The architecture of the cardossier system (see Figure 3) now offers potential for value creation for each stakeholder on two dimensions.

Figure 3: Architecture of the cardossier System

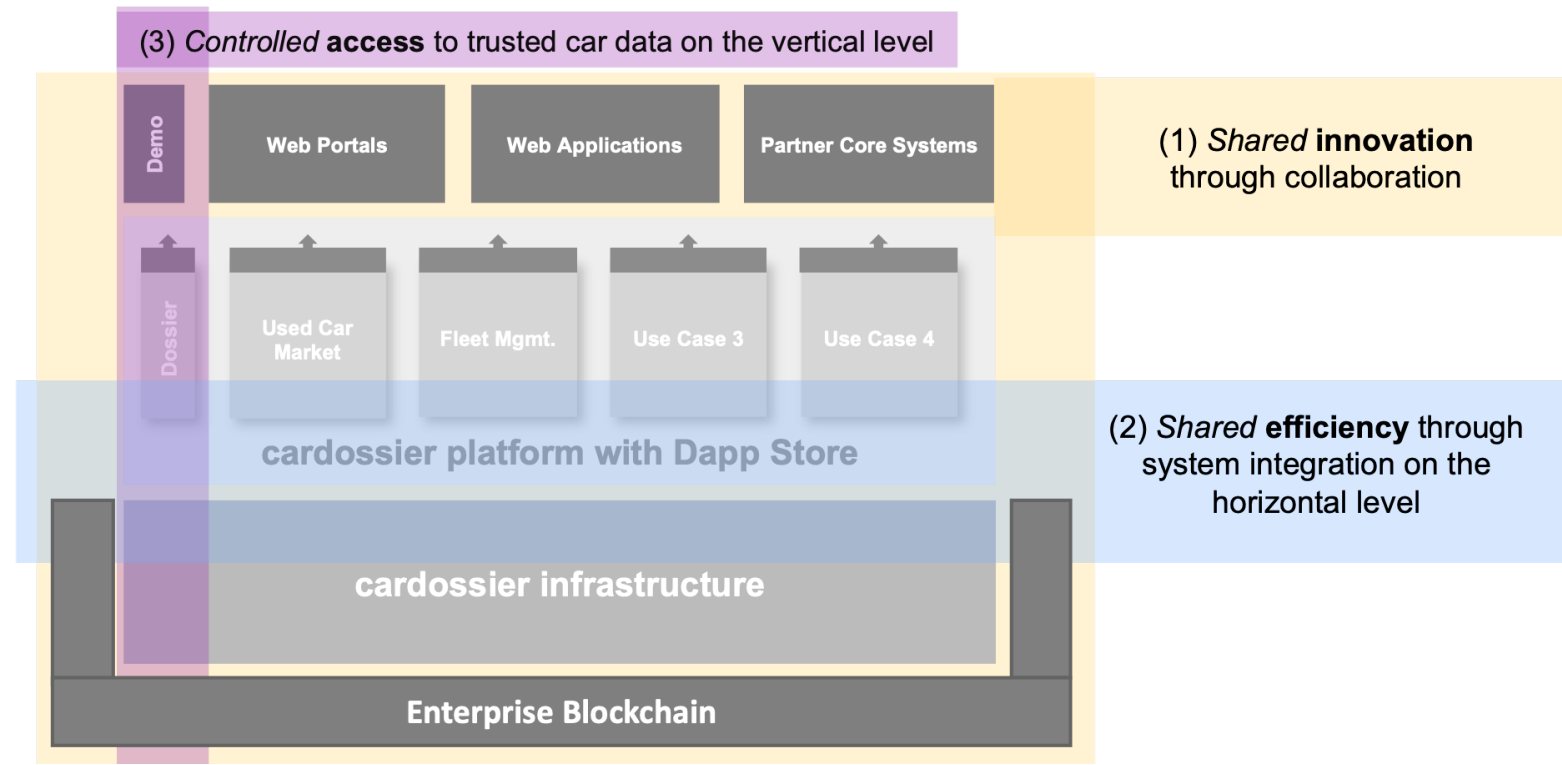

On the vertical dimension, the system offers a peer-to-peer (P2P) market for trusted car data, enabling stakeholders to make use of raw data through P2P data sales and purchases, or to provide services in the form of decentralized applications (available in the "Dapp Store,"27 — the store for distributed apps). On the horizontal dimension, the

\footnotetext{
${ }^{27}$ For a detailed description of Dapps, see What is Web 3.0?, Web3 Developer, May 31, 2019, available at https://web3developer.io/what-is-web-3-0/.
} 
system offers opportunities for shared operational efficiencies through system integration. This integration enables process inefficiencies and sources of failure between two or more business to be resolved.

The three value potentials of the cardossier project for each individual stakeholder ${ }^{28}$ depicted in Figure 3 can be summarized as:

1. Shared innovation through collaboration: the co-creation of a new distributed system architecture across businesses

2. Shared efficiency through system integration: the potential to minimize overhead costs through integrating and sharing processes

3. Controlled access to trusted car data: enabling competitive advantage though deeper insights from data.

In summary, the cardossier system architecture uses blockchain technology as the infrastructure to create a decentralized data storage and data market, on top of which is a platform that allows all participants to create and leverage value through deploying decentralized applications.

Creating an infrastructure, however, is only part of the story. Success for a networkenabling infrastructure such as that being built by the cardossier project depends on making a significant market impact. There were several measures taken by the cardossier project to ensure it reaches the broader market. Initially, the consortium was established as a non-profit organization. Membership was open to all players in the car-related 
ecosystem, and the non-profit nature of the consortium improved the trustworthiness and "good will" of the founding members. Second, public agencies were expected to commit to providing exclusive data to incentivize players such as importers to collaborate.

Moreover, public agencies have regulatory power that, together with their data, means the system is increasingly perceived as a standard in the Swiss market. ${ }^{29}$ The involvement of public agencies could lead to changes in the law that will oblige certain players to provide their data. Third, the large and well-known brands involved in the consortium attracted the attention of the media, public and other organizations, which not only encouraged other organizations to join the consortium, but also spread the word through their business networks. Fourth, the critical mass of authenticated data and its availability was an important driver of adoption. While other platforms often adopt a user-centered approach to growth, focusing first on end users, the cardossier consortium followed a data-centered approach by offering authenticated data to businesses, with those businesses then driving the growth of end users.

When the cardossier consortium was preparing its medium-term financial plan, it evaluated the option of an initial coin offering (ICO) $)^{30}$ in the form of a voting token. This form of token system would have allowed the distribution of voting rights to the initial founding members and potential new entrants. However, the steering committee decided not to pursue this option because it would have meant that the consortium would have to convince participants to commit to the project by viewing it as an investment.

\footnotetext{
${ }^{28}$ The three value potentials are described in more detail in Bauer, I., Liudmila Z., Leisibach, F. and Schwabe, G. "Exploring Blockchain Value Creation: The Case of the Car Ecosystem," in Proceedings of the $52^{\text {nd }}$ Hawaii International Conference on System Sciences (HICSS), Maui, October 2018.

${ }^{29}$ The member from the Road Traffic Agency was appointed as president of the consortium.

${ }^{30}$ For information on blockchain token design, see Oliveira, L., Zavolokina, L., Bauer, I. and Schwabe, G.

"To Token or not to Token: Tools for Understanding Blockchain Tokens," in Proceedings of the $39^{\text {th }}$ International Conference on Information Systems (ICIS 2018), 2018.
} 
Even though voting tokens might have made it easier to gain commitment from the stakeholders, the view was that this approach would have attracted participants with the wrong motivations. Rather than encouraging financial investors to join the project, the consortium aimed to recruit actively participating stakeholders.

At the time of preparing the medium-term financial plan, it was difficult to estimate the value stakeholders would gain from the cardossier project. A rough estimate of potential revenue from the consortium's use-case (the used-car market) existed, but the majority of stakeholders agreed that cardossier offered the potential of much more value from additional business cases that would exploit the data market the project was creating. Thus, the consortium decided to offer members opportunities for future value creation by providing the ability to join development efforts and to design applications that would generate revenue for their individual businesses.

In other words, the cardossier consortium decided to create a membership model that offers different membership categories to potential members. These membership categories not only manage the voting rights (as they would have with the investment approach) but also give members the right, for example, to deploy their own applications in the cardossier platform using the Dapp Store. This approach incentivizes both potential and existing founding consortium members to not only invest financially but also to join development efforts and thus enhance distributed innovation.

The decision not to encourage financial equity stakes was consistent with the overall vision of the cardossier consortium to not directly maximize the value generated for its members. Instead, the consortium set out to create a platform that will enable members to create their own businesses built around cardossier data and be responsible for maximizing their own profits. The consortium is aiming to build an open infrastructure 
and a platform available to all firms from the variety of industries involved in the carrelated ecosystem, not just to selected players.

\section{Resolving Tensions in the cardossier Consortium}

Six key tensions arose during the evolution of the cardossier consortium (see Table 1). We examine these tensions through the paradox ${ }^{31}$ perspective and show how they were resolved. The paradox perspective has two components: (1) a contradiction between two propositions (the tension) and (2) resolution of the tension. ${ }^{32}$ In management science, the paradox perspective offers four coping strategies for resolving a paradox between A and B: (1) Acceptance: keeping A and B separate and their contrasts appreciated; (2) Spatial separation: situating A and B at two different levels of analysis; (3) Temporal separation: switching between A and B in the same location at different points in time; and (4) Synthesis: finding a new perspective that eliminates the opposition between A and B. Below, we show which specific strategies were applied to resolve the paradoxes that arose during the evolution of the cardossier consortium.

\footnotetext{
${ }^{31}$ Schad, J., Lewis, M., Raisch S. and Smith, W. K. "Paradox Research in Management Science: Looking Back to Move Forward," The Academy of Management Annals (10:1), April 2016, pp. 5-64; the authors define paradox as a "persistent contradiction between interdependent elements."

${ }^{32}$ Poole, M. S. and Van De Ven, A. H. "Using Paradox to Build Management and Organization Theories," Academy of Management Review (14:4), October 1989, pp. 562-578.
} 
Table 1: Tensions in the cardossier Consortium and their Resolutions

\begin{tabular}{|c|c|c|c|c|}
\hline Area & \multicolumn{3}{|c|}{ Tensions } & Resolutions \\
\hline \multirow{2}{*}{$\begin{array}{l}\text { Consortium } \\
\text { Management }\end{array}$} & $\begin{array}{l}\text { Creation of a system } \\
\text { to enable trustless } \\
\text { collaboration }\end{array}$ & vs. & $\begin{array}{l}\text { Need for inter- } \\
\text { organizational } \\
\text { trust }\end{array}$ & $\begin{array}{c}\text { Synthesis: } \\
\text { Trust in execution and } \\
\text { maintenance vs. trust in } \\
\text { design }\end{array}$ \\
\hline & $\begin{array}{l}\text { Cooperation and } \\
\text { collaboration }\end{array}$ & vs. & Disintermediation & $\begin{array}{c}\text { Synthesis: } \\
\text { Shaping vs. using the } \\
\text { platform }\end{array}$ \\
\hline \multirow[b]{2}{*}{ Business Value } & $\begin{array}{c}\text { Improving integration } \\
\text { and operational } \\
\text { efficiencies }\end{array}$ & vs. & $\begin{array}{l}\text { Improving market } \\
\text { transparency }\end{array}$ & $\begin{array}{l}\text { Temporal separation: } \\
\text { Short-term vs. long-term }\end{array}$ \\
\hline & Platform & vs. & Infrastructure & $\begin{array}{l}\text { Spatial separation of } \\
\text { system architecture: } \\
\text { Infrastructure vs. } \\
\text { platform with Dapp Store }\end{array}$ \\
\hline \multirow[b]{2}{*}{ Governance } & $\begin{array}{c}\text { Openness to all to } \\
\text { enable comprehensive } \\
\text { coverage }\end{array}$ & vs. & $\begin{array}{c}\text { Selectiveness to } \\
\text { enable } \\
\text { competition }\end{array}$ & $\begin{array}{l}\text { Spatial separation of } \\
\text { system architecture: } \\
\text { Infrastructure vs. } \\
\text { platform with Dapp Store }\end{array}$ \\
\hline & $\begin{array}{l}\text { Hierarchical } \\
\text { effectiveness }\end{array}$ & vs. & $\begin{array}{l}\text { Democratic } \\
\text { efficiency }\end{array}$ & $\begin{array}{l}\text { Temporal separation: } \\
\text { Short-term vs. long-term } \\
\text { Spatial separation of } \\
\text { system architecture: } \\
\text { Infrastructure vs. } \\
\text { platform with Dapp Store }\end{array}$ \\
\hline
\end{tabular}

\section{Consortium Management Tensions}

\section{Creation of a System to Enable Trust-free Collaboration Vs. Need for Inter-}

organizational Trust. Right from the start, the cardossier consortium faced tension between creation of a trustless system for transactions vs. the need for mutual trust between participating organizations. The consortium aimed to create a system for trustless collaboration that would allow individuals and firms to transact without the need to trust each other. However, to jointly work toward this goal, mutual trust between member organizations in the consortium had to be established. Before work started on 
developing the cardossier system, there was much discussion and design activity aimed at finding common ground and understanding needed to establish collaboration. ${ }^{33}$

While blockchain technology offer a trustless environment, it very quickly became clear that the choice of blockchain technology was driven more by economic rationales than by technological considerations. The two key economic rationales that made it clear blockchain technology was the right choice were the needs for collaboration and for power sharing. The consortium businesses understood that to address the lack of trusted car data throughout the lifecycle of a car, all car-related industries and agencies needed to collaborate; only then would the consortium be able to digitize all data relating to a car throughout its lifecycle.

This is how the necessary trust was established between consortium partners. During Phases 1 and 2 (Consortium Formation and Development of the MVP), when membership was restricted to non-competing organizations, it was important to create transparent and open communication, clear information flows and consensual decision making within the consortium. As mentioned earlier, at the start of the formation phase regular meetings and calls were instituted to keep all consortium members up to date and fully engaged. The organizational structure was also established during this phase and the distribution of roles was agreed. There were four organizational components: the steering committee, project management team, operational team and research board.

The steering committee evaluated project results and made decisions about the subsequent development activities. The operational team met face-to-face every three

\footnotetext{
${ }^{33}$ Miscione, G., Goerke,T., Stefan, K. et al., From authentication to 'Hanseatic governance': Blockchain as Organizational Technology, London School of Economics and Political Science, January 2019, available at https://researchrepository.ucd.ie/handle/10197/10575.
} 
weeks and had weekly calls. Given that innovation projects in general involve high levels of uncertainty and are experimental in nature, the operational team adopted the Scrum software development methodology, which enables developers to cope with a high level of volatility in the requirements. The project management team used collaboration tools to maintain communication and project documentation, and to track progress.

To foster a culture of open communication and trust, the consortium decided that members should have equally distributed voting rights. ${ }^{34}$ Several other options for distributing voting rights among members (according to their engagement or capital shares, and the one-member, one-vote model) were considered at the start of the formation phase, but none of these was thought to be appropriate.

In summary, the discussion on trustless collaboration vs. the need for trust shifted from a purely technical to a sociotechnical perspective. As a consequence, this consortium management tension was resolved by separating the perspective on future execution and maintenance from the perspective on design. While the future execution and maintenance perspective requires trust in the benevolence of the whole community and node operators, the design perspective recognizes that trust should first be built up between organizations involved in design activities, and consensual decision making should be applied for crucial design decisions. ${ }^{35}$

\footnotetext{
34 This decision might be reconsidered in the future.

${ }^{35}$ For information on crucial design decisions for blockchain systems, system evolution and the role of trust, see Ziolkowski, R., Parangi, G., Miscione, G. and Schwabe, G. "Examining Gentle Rivalry: Decision-Making in Blockchain Systems," in Proceedings of 52nd Annual Hawaii International Conference on System Sciences (HICSS), Maui, January 2019, available at http:/hdl.handle.net/10125/59891.
} 
Cooperation and Collaboration Vs. Disintermediation. Blockchain solutions often aim to disrupt intermediaries ${ }^{36}$ but, in contrast, individual members of a blockchain consortium aim to leverage the technology to retain their market positions in the future. The agreed long-term goal of the cardossier consortium is to create a decentralized market for data relating to cars. However, through workshops and interviews with stakeholders, the founding members of the consortium realized that this goal should not — and could not—be achieved right away. Thus, the defensive strategy the consortium followed was not to disrupt current established organizations but instead to first enable efficiency increases in inter-organizational processes. These efficiency increases could, of course, be achieved through a centralized solution, but such a solution would be incompatible with the long-term vision of a fully decentralized data market.

The medium-term (shared operational efficiency) goal and the long-term (disruptive innovation) business vision had different business drivers. Operational efficiency would help businesses to achieve quick and effective results from the project, which in turn would result in continued development funding. Achieving the long-term vision depended on the initial data provided for the cardossier system kick-starting a rapid evolution toward a decentralized data market that individual data buyers and sellers could profit from. Focusing initially on operational efficiencies would provide quick benefits for the businesses involved in the consortium but would not close the door on the long-term vision of disruptive innovation.

\footnotetext{
${ }^{36}$ The most obvious example is cryptocurrencies (e.g., Bitcoin), which are a form of digital currency that doesn't involve banks.
} 
By actively participating in the design of the initial system, the founding consortium members gained valuable knowledge that would later help to achieve the long-term vision. Moreover, the consortium gained a time advantage, placing it ahead of possible competitors, either decentralized or centralized, or inside or outside the car-related ecosystem. What's more, individual businesses were able to gain an understanding of the business value of blockchain technology and how they could use it to reposition themselves and survive in the future.

In summary, the cooperation and collaboration vs. disintermediation consortium management tension was resolved by separating the two activities: shaping and codesigning the system to achieve operational efficiencies today, and considering the potential for new business benefits when using the cardossier platform in the future.

\section{Business Value Tensions}

\section{Improving Integration and Operational Efficiencies Vs. Improving Market}

Transparency. Shifting the focus at the beginning of the project from improving market transparency to improving integration and operational efficiencies opened up a new tension between these two aims. While the long-term goal is to bring trust and transparency into the car-related ecosystem, the consortium members realized that problems of data exchange between organizations should be solved first for two reasons. First, a valuable and high-quality cardossier system would not be possible without authenticated data, provided by organizations involved throughout the lifecycle of a car. The system would be less valuable if some organizations do not participate or do not have the motivation or capabilities to provide their data. Second, operational efficiency is a common problem that unites the interests of businesses and can be solved only by businesses that collaborate effectively. This tension and the initial business-to-business 
(rather than consumer-to-consumer) orientation of the cardossier project are closely interrelated.

The long-term vision is to make the whole used-car market more transparent to better serve the needs of car owners-for example, in managing transfers of titles of ownership. Car owners are mostly private individuals. However, the short-term goal is to attract businesses and serve their needs through creating standards for car-related data. One of the reasons for the initial business-to-business orientation is prioritization: it would not be possible or expedient to serve all segments (i.e., business-to-business, business-to-consumer and consumer-to-consumer) from the outset. The long-term vision of creating a consumer-to-consumer platform for the used-car market cannot be achieved without having businesses onboard, so the first priority is to get them using the platform. However, from the beginning of the cardossier project, there were research activities that explored private users' needs and possible usage of the platform.

In summary, the business value tension of improving integration and operational efficiencies vs. improving market transparency was resolved by temporal separation between the short-term and long-term orientations of the cardossier platform.

Platform Vs. Infrastructure. The second business value tension related to whether the cardossier system is a platform with a modular architecture that creates a two-sided market for car-related data exchange, or an infrastructure that enables access to and usage of this data as well as integration of all inter-related processes. From a technical perspective, a platform has a programmable stable core system with modular variable 
components, whereas an infrastructure connects heterogeneous systems and networks. ${ }^{37}$

From an economic perspective, a platform is designed to provide private benefits and is often profit-oriented, and can frequently be updated as the competitive environment changes, whereas an infrastructure is a commodity (and usually non-profit) service that is designed for long-term sustainability. In terms of governance, a platform is governed privately by one company or a consortium of companies and is designed to enable competition, whereas an infrastructure is often governed and maintained by the government, which acts as a monopoly supplier and exerts strong controls over its use.

From the economic and governance perspectives, the cardosssier system can be considered as both a platform and an infrastructure. The ambition is for the system to become a basic infrastructure and the standard for car-related data exchange. Indeed, some of the prerequisites for it becoming an infrastructure are already in place, like government-level support and creating a system for the public good. However, the cardossier system can't become an infrastructure until it has proven its value as a platform with the ability to align the interests of all involved parties. Thus, the future evolution of the system might be termed as "infrastructuralization of the platform." 38 An important feature of the cardossier system is that it not only provides a platform for deploying apps in the Dapp Store, but also provides an infrastructure for accessing highquality authenticated data relating to transactions and events in the car-related ecosystem.

\footnotetext{
${ }^{37}$ Zavolokina L., Spychiger, F., Tessone, C. J. and Schwabe, G., op. cit., 2018.

${ }^{38}$ For more on platformized infrastructures and infrastructuralized platforms, see: (1) Plantin, J.-C., Lagoze, C., Edwards, P, N. and Sandvig, C. "Infrastructure studies meet platform studies in the age of Google and Facebook," New Media \& Society (20:1), August 2016, pp. 293-310; and (2) Ziolkowski, R., Miscione, G. and Schwabe, G. "Consensus through Blockchains: Exploring Governance across interorganizational Settings," in Proceedings of the $39^{\text {th }}$ International Conference on Information Systems (ICIS 2018), 2018.
} 
In summary, the business value tension of platform vs. infrastructure was resolved through spatial separation of the system architecture.

\section{Governance Tensions}

\section{Openness to all to Enable Comprehensive Coverage Vs. Selectiveness to Enable}

Competition. The cardossier consortium is aiming to create both a platform and an infrastructure for car-related data that is open and fair in two ways: (1) any player from the car-related ecosystem may join and leave it; (2) decisions about design, development and strategy require consensus among consortium members. To ensure fairness in both these ways, the consortium needed to establish an appropriate distributed governance mechanism for a blockchain platform that allows a network of different participants to evolve.

However, before focusing on the long-term vision of distributed governance, the consortium had to ensure that it could run successfully in the short term. A stable governance mechanism had to be in place to keep the consortium functioning and to evaluate if the necessary collaboration was achievable on a small scale, and could still be achieved when more members joined in the future. Without collaboration between the initial non-competing consortium members the data would be incomplete. But it became apparent that to address the whole market (all cars in Switzerland), sooner or later collaboration between competing businesses within the same industry segment would also be required.

As discussed earlier, establishing mutual trust and understanding among consortium members was a prerequisite for building the trustless cardossier platform. The 
consortium used well-established IT governance practices to facilitate collaboration and establish off-chain ${ }^{39}$ governance. However, blockchain technology provides new opportunities and challenges, in particular for predefining rights and decisions and executing them by code, and thus automating them as a part of on-chain ${ }^{40}$ governance. The consortium therefore needed to determine, up front, the rules that would govern the platform; once the rules had been determined, it would be hard to reach a consensus to change them. ${ }^{41}$

Initially, each industry sector was represented by one business in the consortium, so there was little competition among the members. However, the overall goal is that multiple (ideally all) firms from all car-related industries will eventually join the consortium and provide their data so that the cardossier system can cover the entire used-car market. Achieving this vision not only requires a decentralized solution, but also needs a platform with a more modular architecture. A modular architecture will allow consortium members to create their own services on top of the platform, and thus move competition in the market from the physical to the digital, blockchain-based, space.

While the founding members of the consortium agreed that the long-term aim is to expand to the broader market, achieving this remains one of the prominent challenges and risks for the consortium. When competing businesses begin to join the consortium, ${ }^{42}$ the initial cooperation relationship will change to one of "coopetition." As well as

\footnotetext{
${ }^{39}$ Off-chain processes are performed without the help of blockchain technology.

${ }^{40}$ On-chain processes involve smart contracts, which are agreed upon, encoded and immutable within the blockchain system.

${ }^{41}$ For more information, see, Miscione, G., Goerke,T., Stefan, K. et al., op., cit., January 2019.

42 After drafting this article, several competing businesses have joined the consortium (as of autumn 2019).
} 
creating a common good - the cardossier infrastructure - and achieving common benefits, like cost reduction, easier access to data and knowledge, the participating businesses will still compete against each other with their products and services and in the ways they leverage the data obtained from the cardossier system.

In summary, the governance tension of openness to all to enable comprehensive coverage vs. selectiveness to enable competition was addressed by spatial separation of the cardossier infrastructure and platform. The infrastructure provides access to the data and regulates data exchange, whereas the platform with its Dapp Store facilitates competition between consortium members.

Hierarchical Effectiveness Vs. Democratic Efficiency. A second governance tension existed from the moment the cardossier consortium was founded. Although the vision is for democratic governance with decision making supported by blockchain technology - i.e., on-chain governance - the consortium decided to initially implement a simplistic and more traditional hierarchical governance structure-i.e., largely off-chain governance. This decision was driven by the innovative character and high level of risk of the initiative, and by the need to later expand the consortium. It was essential to start with a governance structure that would facilitate an effective working organization able to bring the cardossier system quickly to market and create a vibrant ecosystem around it.

To implement this governance structure, a strong board of directors was appointed, along with executive-management and operational teams. The advantages of this approach are that board members, the CEO and the cardossier office steer the consortium relatively autonomously while taking account of members' wishes, which allows for faster decision making, at least by senior management. The approach also allows 
consortium members to safeguard their interests more easily as they can exercise control locally. And, as mentioned earlier, adhering to a specific legal framework provides advantages for structuring cooperation, both for development efforts for resolving any conflicts - e.g., concerning the reversal of transactions or disputes about ownership. Thus, as the consortium prepares for market entry, the governance priorities are hierarchical effectiveness and legal considerations.

In the longer term, however, the governance focus will switch to democratic efficiency, when decision making, assessing the impact of individual players and reaching consensus are supported by blockchain technology. In this respect, blockchain technology can be thought of as a kind of accounting system where a blockchain token could represent one vote. To make voting distribution fairer, smart contracts could automatically update voting rights in line with a consortium member's activity and involvement in terms of, for example, financial contribution, code contribution, voting activity or data correction. Many of these activities are conducted on-chain or at least in a digital form, which may serve as data feeds to the cardossier system. Note that voting and assessing a member's involvement takes place on-chain via code and does not rely on an intermediary.

With these potentials of blockchain technology in mind, the consortium decided to postpone the implementation of a full-blown on-chain governance until the cardossier ecosystem was more stable. In other words, the governance tension of hierarchical effectiveness vs. democratic efficiency was resolved by temporal separation of the shortterm and long-term goals as well as through spatial separation of the system architecture. 


\section{Insights from the cardossier Project}

We gained three insights from our involvement in the cardossier project. These insights will be of value to enterprises considering whether to join and collaborate in a blockchain consortium.

\section{Blockchain Solutions Encourage Collaboration, but Require Initial Mutual Trust}

The reasons for enterprises engaging in blockchain-enabled inter-organizational collaboration include curiosity and interest in a new technology, its promised business benefits (trust, transparency and efficiency, resulting in cost savings), fear of missing out or being disrupted, and access to new forms of collaboration. This article has shown that one form of collaboration is to join a blockchain consortium. However, mutual trust within the consortium is an important aspect to achieve success in this collaboration. Thus, when deciding whether to join a consortium, digital transformation leaders should seek answers to the following questions: Who are the collaborators? Are they ready to shift their mindset to create a common good that can also bring benefits to individual consortium members in the longer term? Are they ready to share financial costs and intellectual property rights? What does the collaboration mean for their organizations?

The cardossier case study shows that starting with a "vertical" consortium (i.e., one where most members do not compete with each other) reduces the risk of unnecessary conflicts between competitors that might kill the project in an initial phase. This type of consortium also provides consortium members with a better understanding of related businesses and business processes. However, for a consortium to be successful in the long run its blockchain solution will have to widely adopted, and to achieve this participants should be prepared for the challenges of moving to a "horizontal" consortium where members compete against each other. 


\section{Blockchain Technology Enables Distributed Value Generation in a Digital Ecosystem}

Permissioned blockchains provide an opportunity to transfer market principles and rules from the physical to the digital world, thus, enabling distributed value generation in a digital ecosystem. Blockchains, per se, do not eliminate competition or create a monopoly. A blockchain platform where players know each other allows a more transparent and trusted environment in which each player can conduct its daily business, create a competitive advantage in the market and provide value for its customers. Although the ecosystem around a blockchain can only be created collaboratively, each enterprise in a blockchain consortium can gain individual benefits from the technology. Achieving these individual benefits, however, requires a clear separation of long-term and short-term priorities and market orientations. Initially, consortium members should focus on resolving inter-organizational efficiency problems (i.e., a business-to-business market orientation) and only later address the business-to- consumer and consumer-toconsumer markets.

\section{Laws and Regulations are Key to the Success of Blockchain Projects}

Blockchains authenticate data and transactions and allow the transfer of digital value, functions that traditionally are governed by legal regulations. Laws and regulations can enable and drive blockchain innovation but can also hinder it. Regulators can play different roles in a blockchain consortium. They can act as supporters who transfer the regulatory requirements into the development, or as gatekeepers who control and incentivize data quality, or as orchestrators who enable and intervene in situations that require settlement. Moreover, a blockchain consortium should be established as a legal entity, which will facilitate the combining of on-chain and off-chain governance functions and foster market penetration and standardization. Although some governance 
functions may be "outsourced" to blockchain code (in the form of smart contracts), making them more efficient, the reality is that off-chain governance is still needed where the technology reaches its limits. At first glance, collaborating through a blockchain consortium might seem to be primarily concerned with the technology itself, but governance and legal considerations also play an important role and cannot be ignored.

\section{Concluding Comments}

The growing number of blockchain consortia is providing both opportunities for new forms of collaboration built around the potential benefits of blockchain technology, and uncertainty caused by the tensions such collaborations bring. In this article, we have provided insights from the way the cardossier blockchain consortium faced and resolved these tensions, which arise in three areas - consortium management, business value and governance. The cardossier consortium is an example of a new type of blockchain collaboration that requires structures and governance mechanisms that may differ from traditional ones.

Blockchain technology is not only an enabler of inter-organizational collaboration. It also facilitates the way businesses transact with each other and leads to a new type of organization (a blockchain consortium) that has a distinctive governance structure and legal foundation. However, there is still much work to be done to understand how blockchain consortia and their platforms become blockchain organizations and ecosystems. Reports on the experiences of enterprises involved in endeavors such as the cardossier consortium are a valuable step in the right direction. 


\section{Appendix: Research Methodology}

This study is a part of a larger Action Design Research"3 project (the "Blockchain Car Dossier"), funded by Innosuisse. This project is an example of how information systems research moves through "the last research mile" 44 and uses solution-based probing ${ }^{45}$ to assess the viability of an innovation and create deeper understanding of design rationales. Such projects move from proof-of-concept to proof-of-value, finally reaching proof-of-use. Proof-of-concept research demonstrates the existence of an important class of unsolved problems along with the technical feasibility of a solution. Proof-of-value research demonstrates empirically the potential worth of a solution in lab or field studies. Proof-of-use research demonstrates that a self-sustaining and growing community of practice has emerged around the solution.

All authors of this article are involved in the design and development of the proposed cardossier platform as well as in setting up the consortium, including the business model and governance. The cardossier case study presented in this article is based on interviews with project partners, project documentation, data from workshops and regular project meetings, and observations. These activities ran from November 2016 to February 2019.

\footnotetext{
${ }^{43}$ Maung K. S., Henfridsson, O., Purao, S. and Rossi, M. “Action Design Research,” MIS Quarterly (35:1), March 2011, pp. 37-56.

${ }^{44}$ Jay, F. N., Briggs, R. O., Derrick, D. C. and Schwabe, G. "The Last Research Mile: Achieving Both Rigor and Relevance in Information Systems Research," Journal of Management Information Systems (32:3), July 2015, pp. 10-47, available at https://doi.org/10.1080/07421222.2015.1094961.

${ }^{45}$ Böhmann, T., Schwabe, G., Briggs, R. O. and Tuunanen, T. "Advancing Design Science Research with Solution-based Probing," in Proceedings of the $52^{\text {nd }}$ Annual Hawaii International Conference on System Sciences (HICSS), Maui, January 2019.
} 


\section{About the Authors}

\section{Liudmila Zavolokina}

Liudmila Zavolokina (zavolokina@ifi.uzh.ch) is a researcher in information systems at the Information Management Research Group at the University of Zurich, Switzerland. Her research interests include blockchain platforms and their impact on trust relationships, blockchain-based incentive systems and digital innovation in the financial area (FinTech). Liudmila co-initiated the cardossier project and leads its research team.

\section{Rafael Ziolkowski}

Rafael Ziolkowski (ziolkowski@ifi.uzh.ch) is a doctoral student and research assistant at the Information Management Research Group at the University of Zurich, Switzerland. His research interests include the intersection of technology and modes of organizing, inter-organizational system governance, studying the applicability of blockchain to various use-cases, and blockchain technology in general. Rafael codeveloped the Innosuisse grant application for the cardossier project and led the governance-related work. He holds Bachelor's and Master's degrees in Information Systems from the University of Duisburg-Essen, Germany.

\section{Ingrid Bauer}

Ingrid Bauer (bauer@ifi.uzh.ch) is a doctoral student at the Information Management Research Group at the University of Zurich, Switzerland. Her research focuses on blockchain business models and data markets. Ingrid led the definition of the cardossier project's business model for the used-car market and worked on the design of the cardossier data market. She also acts as the Scrum Master for the development team. Ingrid holds a BSc in Information Engineering and Management from the Karlsruhe 
Institute of Technology and an MSc in Information Systems from the Copenhagen Business School.

\section{Gerhard Schwabe}

Gerhard Schwabe (schwabe@ifi.uzh.ch) has been a full professor at the University of Zurich since 2002. Since starting as a researcher in 1988, he has studied collaboration at the granularity of dyads (groups of two), small teams, large teams, organizations, communities and social networks. In this research, he follows either an engineering approach ("design science") or an exploratory approach—frequently in collaboration with companies and public organizations. His work has been published in the proceedings of computer science and major information systems conferences, and in computer science journals. Gerhard's current research focus is on blockchain applications and human-robot collaboration. 